6-1999

\title{
Instruction, Capacity, and Improvement
}

David K. Cohen

Deborah Loewenberb Ball

Follow this and additional works at: https://repository.upenn.edu/cpre_researchreports

Part of the Curriculum and Instruction Commons, Curriculum and Social Inquiry Commons,

Educational Administration and Supervision Commons, Educational Methods Commons, Education Policy Commons, and the Teacher Education and Professional Development Commons

\section{Recommended Citation}

Cohen, David K. and Ball, Deborah Loewenberb. (1999). Instruction, Capacity, and Improvement. CPRE Research Reports.

Retrieved from https://repository.upenn.edu/cpre_researchreports/8

View on the CPRE website.

This paper is posted at ScholarlyCommons. https://repository.upenn.edu/cpre_researchreports/8

For more information, please contact repository@pobox.upenn.edu. 


\title{
Instruction, Capacity, and Improvement
}

\begin{abstract}
Since World War II, efforts to improve schools have numbered in the thousands. Most efforts have concentrated on improving the curriculum materials used in schools or on "training" teachers in new instructional methods. Many of these efforts have gone under the banner of "building instructional capacity," a term that for decades has been featured prominently in conversations about educational reform. Unfortunately, three decades of research has found that only a few interventions have had detectable effects on instruction and that, when such effects are detected, they rarely are sustained over time. A review of research and professional experience with school improvement suggests several explanations for these disheartening findings. One is that schools are complex social organizations situated within, and vitally affected by, other complex social systems including families, communities, and professional and regulatory agencies. The larger social environment of schools constrains and shapes the actions of teachers, students, and administrators, often in ways that greatly complicate the work of school improvement. Challenges to school improvement are particularly acute in highpoverty settings where recruiting wellqualified teachers is difficult and where the emotional and health problems of students often deflects attention to educational issues or impedes work on them. As a result, many researchers now believe that school improvement involves much more than efforts to change interactions occurring within schools. To succeed, school improvement interventions also must attend to the complex relationships that exist among intervention agents, schools, and their social environments.

Disciplines

Curriculum and Instruction | Curriculum and Social Inquiry | Educational Administration and Supervision | Educational Methods | Education Policy | Teacher Education and Professional Development
\end{abstract}

\section{Comments}

View on the CPRE website. 


\title{
Instruction, Capacity, and Improvement
}

\author{
David K. Cohen and Deborah Loewenberg Ball
}

CPRE Research Report Series

RR-43

June 1999

Consortium for Policy Research in Education

University of Pennsylvania

Graduate School of Education

(C) Copyright 1999 by the Consortium for Policy Research in Education 



\section{Contents}

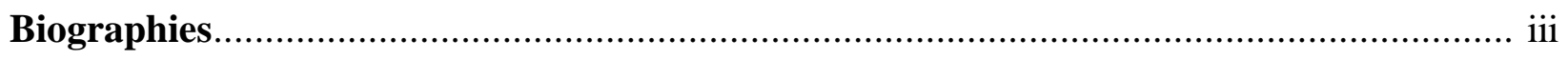

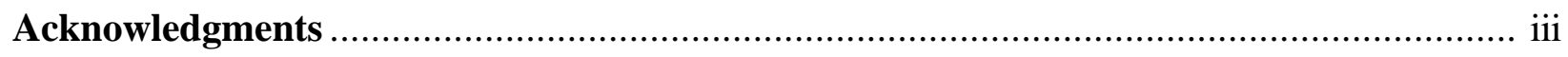

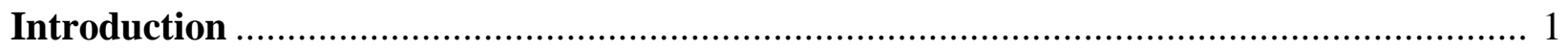

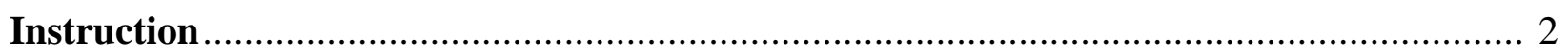

Implications for Intervention and Research ..................................................... 7

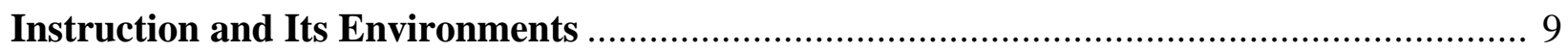

Issues and Implications for Intervention and Research .......................................... 14

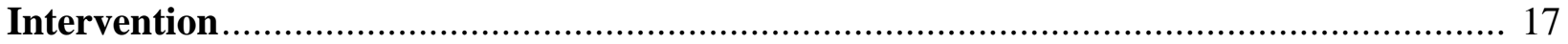

Implications for Intervention and Research ....................................................... 20

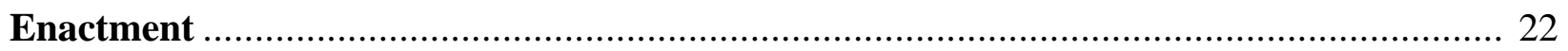

Implications for Intervention and Research .................................................... 26

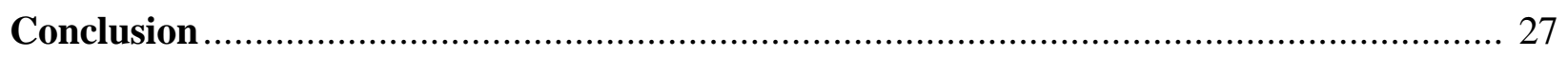

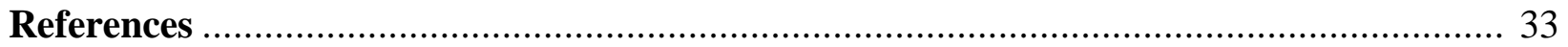

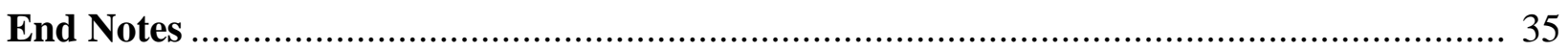




\section{Biographies}

David K. Cohen is John Dewey Collegiate Professor of Education, and Professor of Public Policy at the University of Michigan. In addition to his current work on educational policy and the relationships between policy and practice, his previous research includes studies on the effects of schooling; efforts to reform teaching; evaluation of educational experiments and large-scale intervention programs; and relations between research and policy.

Deborah Loewenberg Ball is professor of education at the University of Michigan. With elementary school mathematics as the main context, her research focuses on the challenges of teaching for understanding and on efforts to support such teaching through policy, reform initiatives, and teacher education. Her publications include articles on teacher learning and teacher education; the role of subject matter knowledge in teaching and learning to teach; challenges embedded in trying to teach for understanding; and relations of policy and practice in instructional reform.

\section{Acknowledgments}

The research reported in this paper was supported by a grant (No. OERI-R308A60003) to CPRE from the National Institute on Educational Governance, Finance, Policymaking and Management, Office of Educational Research and Improvement, U.S. Department of Education. The views expressed in this report are those of its authors and are not necessarily shared by the U.S. Department of Education, CPRE, or its institutional members. 


\section{Introduction}

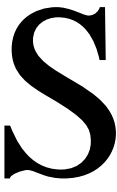
ince World War II, efforts to improve schools have numbered in the thousands. Most efforts have concentrated on improving the curriculum materials used in schools or on "training" teachers in new instructional methods. Many of these efforts have gone under the banner of "building instructional capacity," a term that for decades has been featured prominently in conversations about educational reform. Unfortunately, three decades of research has found that only a few interventions have had detectable effects on instruction and that, when such effects are detected, they rarely are sustained over time.

A review of research and professional experience with school improvement suggests several explanations for these disheartening findings. One is that schools are complex social organizations situated within, and vitally affected by, other complex social systems including families, communities, and professional and regulatory agencies. The larger social environment of schools constrains and shapes the actions of teachers, students, and administrators, often in ways that greatly complicate the work of school improvement. Challenges to school improvement are particularly acute in highpoverty settings where recruiting wellqualified teachers is difficult and where the emotional and health problems of students often deflects attention to educational issues or impedes work on them. As a result, many researchers now believe that school improvement involves much more than efforts to change interactions occurring within schools. To succeed, school improvement interventions also must attend to the complex relationships that exist among intervention agents, schools, and their social environments. A new idea which has developed in the last decade is that successful school improvement in high-poverty schools requires external interventions that are capable both of making large and lasting changes in instructional capacity, and doing so under conditions that rarely support and often impede such work.

A second explanation for the typically small effects of school improvement interventions is that most are not designed to provide the opportunities for teacher learning that would be needed to change classroom instruction. Even when interventions explicitly introduce new curricular materials or provide teacher "training," they rarely create adequate conditions for teachers to learn about or develop the knowledge, skills, and beliefs needed to enact these interventions successfully in classrooms. For example, new materials are often brought into schools without sufficient guidance about how they are to be used with particular students. Teachers are rarely offered opportunities to learn more about either the subject matter content they are being asked to teach or about how students think about that content. Neither is it common to provide teachers with opportunities for guided practice or reflection on how new teaching strategies are working in their classrooms. Instructional interventions are commonly introduced into schools without taking adequate account of what it would take to make them work in classrooms. Interventions are often made as though their mere introduction could change instruction. Despite the fact that this strategy has rarely worked, adopting new curriculum materials, for example, is one of the most widely used interventions.

In the last several years, a number of new interventions ${ }^{1}$ have been invented and set in motion that are different in focus, design, and approach than previous efforts to improve schools. All of them envision more comprehensive strategies for school im- 
provement. For example, many focus both on preschool as well as elementary schools. Many try to involve parents in students' academic work. Many focus on improving professionals' collegial interactions, or on coordinated improvements in the teaching of particular academic subjects. The intervenors vary, from state agencies to national reform networks, and the interventions also vary, from new curricula to whole school reform. Despite their differences, they share some critical features. One is that they envision much more comprehensive change efforts than those of the past. A second is that, in one way or another, they all seek to improve teaching and learning, and they all focus on students who have been poorly served by schools. A third is that they work from a position external to schools to improve what happens inside. $^{2}$

At the same time, differences among these interventions highlight alternative strategies for comprehensive instructional improvement. For example, the targets of their work differ. Some aim chiefly at reading instruction; others target schools' decision-making processes; still others focus on communities and children's welfare; and some target curriculum.

These interventions represent a new course of action in school improvement, and this report offers a theoretical frame for examining these efforts at instructional improvement. Since our analysis centers on instruction, we begin there: we first develop a theoretical view of instruction and then an analysis of the environments of instruction. These two elements offer a basis for analyzing the relations between instruction and its environments, and for representing the circumstances in which intervenors must operate. We turn then to a discussion of the problems and possibilities for intervention.
The theoretical frame that we offer is instructional. We develop an interactive model of instruction to analyze both teaching and efforts to improve teaching. We elaborate this split-level frame as we go, drawing out implications for understanding instruction, instructional improvement, and research on the two. We conclude by summarizing the ideas and distinguishing them from other approaches to understanding and studying school improvement. ${ }^{3}$

\section{Instruction}

Instructional capacity is prominently featured in the contemporary conversation about educational reform. This capacity is widely regarded as critical to good teaching and learning, and capacity-building is often depicted as the key to better education. Though reformers have frequently aimed to improve what students learn, most efforts to increase learning-which number in the thousands since World War II-have concentrated on a single factor: improving curriculum materials, training teachers in new methods, or adding new technology. Following this logic, reformers seem to have assumed that increasing the instructional capacity of schools depends on increasing the capacity of either teachers or the materials they use. There is increasing evidence that such efforts rest on very partial conceptions of instructional capacity.

Capacity and Interaction. We focus on the interactions among teachers and students around educational material, rather than seeing curriculum alone or teachers alone as the main source of instruction. On this view, each of the three elements is essential, but instruction requires all three. Instructional capacity-the capacity to produce worthwhile and substantial learning-is a function of the interaction among these elements, not the sole province of any single 


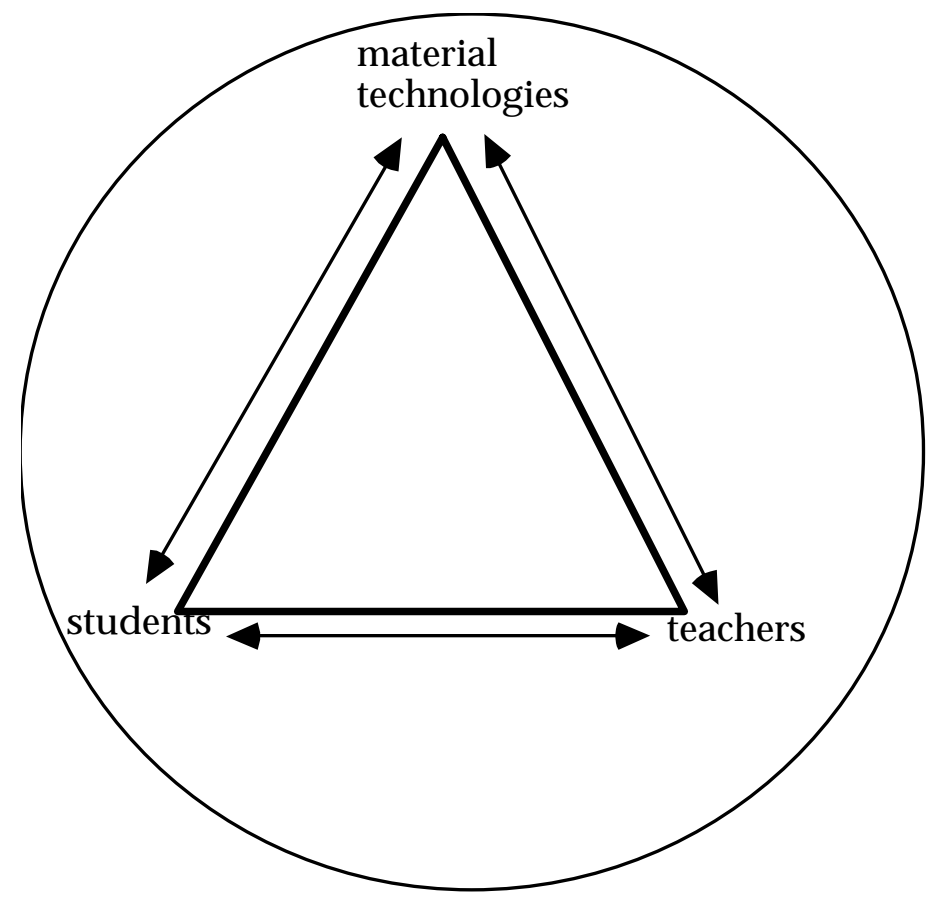

one, such as teachers' knowledge and skill, or curriculum. We briefly discuss each element and its relation to the others.

Teachers' intellectual and personal resources influence instructional interactions by shaping how teachers apprehend, interpret, and respond to materials and students. There is considerable evidence that teachers vary in their ability to notice, interpret, and adapt to differences among students. Important teacher resources in this connection include their conceptions of knowledge, understanding of content, and flexibility of understanding; acquaintance with students' knowledge and ability to relate to, interact with, and learn about students; and their repertoire of means to represent and extend knowledge, and to establish classroom environments. All these resources mediate how teachers shape instruction. Consequently, teachers' opportunities to develop and extend their knowledge and capabilities can considerably affect instruction by affecting how well teachers make use of students and materials.

Most discussion of capacity has focused on teachers, but much research shows that students' experiences, understandings, interests, commitments, and engagement are also crucial to instructional capacity. One way to consider the matter is that the resources that students bring influence what teachers can accomplish. Students bring experience, prior knowledge, and habits of mind, and these influence how they apprehend, interpret, and respond to materials and teachers. The same mathematics problem used by the same teacher may produce a substantially different lesson with a group of students at one point than it might after students learn things that affect their approach to the task. When teachers say, "My students could never do that," they do not recognize the ways in which students could learn or change. Students-and interactions among students-shape the resources for their own learning. 
By materials we mean what students are engaged in, as presented in texts and other media, as well as in problems, tasks, and questions posed to students. Instructional materials can mediate students' engagement with the content to be learned, though sometimes the materials themselves are what is to be learned. They can be thought of as the material (as opposed to social) technologies of instruction, including print, video, and computer-based multimedia.

Curriculum is often developed in advance, but students' and teachers' interactions with this material comprise the enacted-which is to say, the actual or effective-curriculum. ${ }^{4}$ These material technologies influence instructional capacity by constraining or enabling students' and teachers' opportunities to learn and teach. Features of these technologies that seem likely to affect instructional capacity are their complexity and the design of teachers' and students' intended engagement. In the case of mathematics materials, we would expect that the nature of the problems offered, the development of the ideas, the number and variety of representations, and the ways in which multiple representations were coordinated would shape what teachers and students could do and learn.

It follows from this analysis that any given element of instruction shapes instructional capacity by the way it interacts with and influences the other elements.

Capacity Not Fixed. If this last point is roughly right, then capacity is not a fixed attribute of interactions. One teacher's interactions with a class of fifth graders, for example, will yield greater instructional capacity than those of a colleague who works with the same class, because the first teacher is more adept at evoking and making use of students' ideas. This means that speaking in terms of what teachers or students "bring" to interactions may be misleading, since what students and teachers bring may be used to better or worse advantage by others. In discussing what students bring to a task it is important to recognize that it depends in part on what teachers can see and use in students. One reason that different teachers elicit different responses and work from the same students is that what teachers know, believe, and can do shapes their perceptions of what students bring, the opportunities they subsequently extend to students, and their interpretation of students' ensuing work.

Similarly, materials both depend on their use by students and teachers and affect such use. From one perspective, the use of reading materials would be shaped by the nature of the text they offer students, and the approaches used to develop students' reading, comprehension, and interpretation. From another perspective, materials are shaped by students' ideas and experiences. But here we can see teachers' unique position in the construction of instructional capacity.

Teachers' knowledge, experience, and skills affect the interactions of students and materials in ways that neither students nor materials can. That is because teachers mediate instruction: their interpretation of educational materials affects curriculum potential and use, and their understanding of students affects students' opportunities to learn.

As teachers learn new things about content and students, they notice different things about both, and are able to use them differently. Change in students, teachers, or materials has the potential to change the relations of teachers, students, and materials, and hence affect instructional capacity. But change in teachers has unique potential, because teachers mediate all relationships within instruction. 


\section{Purposes, Professional Knowledge, and}

Capacity. Differences among interactions are not the only source of variation in instructional capacity. Capacity also seems to depend both on conceptions of professional knowledge and on the aims, content, and methods of instruction. Some uses of the term "capacity" focus on space and storage, while others focus more on growth and change. In the first case, capacity denotes a finite set of knowledge, skills, and commitments that are needed in order to produce good instruction, but in the second it denotes the construction of new knowledge and skills in practice.

Though much instruction lies somewhere between these two poles, they represent two quite different conceptions of the relationship between knowledge and practice, and thus instructional capacity. Roughly speaking, the first view envisions capacity as a storehouse that contains fixed resources needed for instruction. These would include teachers' subject matter knowledge, skills, and commitments, their knowledge of students, and the content of instructional technologies, among many other things. ${ }^{5}$ From this vantage point, having capacity refers chiefly to the extant body of teachers' knowledge and skill, the content of instructional technologies, and the adaptation and application of that knowledge in particular situations. ${ }^{6}$ On the second view, however, capacity is envisioned as a source and creator of knowledge and skills needed for instruction. Teachers would improve practice by investigating teaching and learning, either in situ or in situations that derived from practice. Rather than only drawing on or delivering a fixed stock of knowledge, teachers would learn from practice in ways that generated more resources for subsequent teaching. ${ }^{7}$ They would learn about how students think about particular ideas, how certain representations of content work, what some common difficulties are that students encounter, and ways to mediate those difficulties.

The aims, content, and methods of instruction also shape conceptions of capacity. For instance, philosophers of education and observers of instruction regularly distinguish between teachers who cultivate students' reasoning or sense-making and those who inculcate facts and skills. Such differences apply to apparently different capacities. What instructional technologies would have to contain, and what teachers would need to know and be able to do, could vary enormously between these two aims. The differences can be arrayed on several analytically and practically distinct domains. One is how instructional technologies and teachers treat knowledge: some take it as though it was fixed, given, and settled, while others take it as open, constructed, and disputed. A second is how instructional technologies and teachers deal with students' thinking: some ignore it, others focus on very limited channels, and still others support active investigation of students' knowledge and ideas, using them as a central orientation for instruction. A third is how instructional technologies and teachers address and organize classroom discourse: some treat it as a matter of one-way transmission from teachers to learners, others as recitation, and still others as creating conversations. ${ }^{8}$ In each of these dimensions, instruction that was at one extreme would require different knowledge and skills than instruction that was at the other; hence capacity-what it takes to produce instruction-also would vary.

Instructional aims, content, and methods interact with conceptions of professional knowledge: different conceptions of professional knowledge co-exist with different methods and purposes of instruction. For example, if capacity means learning in and 
from practice, it can refer to instruction in which knowledge is seen either as facts and information or as intellectually ambitious, uncertain, and contested. In the first case, learning in and from practice would refer to relatively straightforward learning in a relatively bounded set of domains. Teachers who employed Instructional Theory into Practice would be an example of this alternative: they would try to improve students' learning by learning in practice-adapting instruction to the students, monitoring students' work, and revising instruction in consequence-but they would do so within a type of direct instruction that focused on facts, skills, and procedures. In the second sort of instruction, however, learning in practice would be much more complex; for if knowledge is interpretive, and thus often ambiguous, it is more difficult for materials and teachers to represent knowledge for students than if they define it as facts and skills. It would be even more difficult and complex for teachers who held knowledge as interpretive and complex to try to apprehend and interpret students' thinking.

This discussion suggests that capacity would in part be a variable function of the prevailing goals and methods of instruction and of the nature of professional knowledge. These things would influence instructional capacity through the content of instructional technologies and the ideas and beliefs of students and teachers.

Capacity, Time, and Mobility. Instruction can only be examined in time. One reason is that the interactions described above accumulate. Teachers and students interact over materials over the course of many days, hence instruction is a composite of relations among teachers, students, and materials over time. Another reason is that learning occurs over time. Learning to read text competently, to calculate sums and differences, or to interpret and solve problems are accomplishments attained gradually. No single lesson leads to achieving the main goal of instruction; learning occurs in fits and starts, sometimes clearly linked to instruction, sometimes less easily traced.

A third reason is that instruction and the elements that comprise it change over time. Some of this change is variability: a crosssection of instruction at one point in time captures only one slice of a highly variable set of slices. Materials may differ in subtle ways from day to day, teacher and students may interact differently, or what students or teachers bring to the topic at hand may vary. Given the unpredictability and variability of the interactions, it makes sense to think of instructional capacity in terms of central tendencies or other attributes of streams of interaction, rather than a slice. However, some change in instruction is a product of changes in its elements or in their relations with one another. Teachers and students may learn, change their minds, or move away. Different materials may be used, or their role may shift. As they change, capacity also changes.

Precisely because teachers, students, and materials develop and change, instability is critical. Two sources of instability may be particularly salient in high-poverty schools:

- Individual students often do not interact on a continuous basis with one teacher for instruction in reading or mathematics. Teachers may be absent, paraprofessionals or volunteers often are used heavily, and low-achieving students are often regrouped for instruction. Students shuttling among several instructional situations can threaten instructional continuity and coherence. 
- Students often move in and out of schools within a single year; student mobility rates of some schools can be higher than 50 percent in one year. Such mobility creates another version of the variability in instructional situations discussed above. It also affects instruction itself, for as students move in and out of the classroom, the social and intellectual resources of instruction shift-including such matters as students' relations with one another, norms of discourse, ideas and experiences available to the group, and patterns and substance of group interaction.

\section{Implications for Intervention and Research}

We pause to note several implications of the analysis sketched above.

Comprehensiveness and Intervention. If instructional capacity is a property of interactions among teacher, students, and materials, then interventions are likely to be more effective if they target more interactions among more elements of instruction, rather than focusing on one element in isolation from others. Interventions that focus not only on aspects of particular elements, but also on their relations, are more likely to improve capacity.

Interventions need not act directly on all elements-on teachers, students, and materials. Those that work indirectly on all three elements could be more effective than interventions that work directly only on one element. For example, one intervention might work on teaching parents to improve students' motivation and to attend school events. Another intervention might do these things and also help parents learn to work with children on the curriculum that the children study. Still another intervention might do all these things while also helping teachers improve their knowledge of the students' curriculum and be more receptive to working with parents. We expect that change agents of the second sort would be more effective than those of the first sort, and that agents of the third sort would be most effective of all, precisely because the second and third interventions have more leverage on more elements of instruction. ${ }^{9}$

These points imply a new perspective on the role of curriculum in building capacity. Efforts to make change through materials have frequently proved disappointing because they have failed to consider either teachers' or students' role in learning to use the materials. ${ }^{10}$ But curriculum development could take account both of teachers' opportunities to learn and of students' likely approach to the material. If intervenors designed materials to anticipate teachers' and students' needs, interpretations, and use-thus attending to students and teachers through the design of new materials-we expect that teachers' and students' opportunities to learn would increase, and that materials would be used to better effect. ${ }^{11}$

Teachers' Unique Role. Interaction is central to our analysis; still teachers' knowledge, skills, and beliefs are distinctively important for teachers interpret the materials with which they work, and these interpretations often change the aims, methods, and outcomes of a curriculum.

One implication is that instructional capacity is partly a function of what teachers know students are capable of doing and what teachers know they are professionally capable of doing with students. We do not mean that any student can do anything a teacher believes he or she can or that all curricula could be surpassingly good if only teachers used them well. Rather, we mean that every 
student and curriculum is a bundle of possibilities, and teachers whose perceptions have been more finely honed to see those possibilities, and who know more about how to take advantage of them, will be more effective. We use the term "know" what students are capable of doing rather than "believe," because we suspect that this is more a matter of professional knowledge than general belief. Most teachers report that they believe their students are capable of fine work, but what they think they know from daily experience often hedges that belief with limited expectations.

These ideas have particular salience in highpoverty schools, where teachers tend to believe that students are capable of only modest work, think that the students' families are to blame, and claim they can do no more than they already are doing. These kinds of ideas about students and their abilities are likely to mediate the implementation of an intervention that aims to improve student performance. But interventions that systematically create opportunities for teachers to learn different facts about their students may challenge these beliefs. To do so, intervenors would have to devise ways for teachers not only to teach specific academic materials differently, but also to see their students as capable of performing well with them. Hard evidence that students were doing work that teachers previously thought they could not do might lead teachers to provide more challenging opportunities for their students.

It follows that instructional capacity is crucially linked to interactions in which teachers and students gain knowledge about what work they can do. Being confronted with evidence of student learning provides teachers with evidence of student capability, and indirectly, of their own capability. The more that evidence matches and exceeds conventional measures of student perform- ance, the more convincing it will be. For example, mathematics assessments that include measures of students' computational fluency along with reasoning and problemsolving will be more persuasive than assessments that only measure elements of mathematical knowledge and competence untapped by traditional assessments.

Teachers' ability to perceive and use students' capabilities is affected by their acquaintance with students' performance and by their understanding of the material. Being able to hear what students are saying, and to see evidence of their thinking and understanding, depends on teachers' knowledge of the terrain in which students are working, and their knowledge of students' thinking. For example, knowing that mathematics requires looking for patterns and making conjectures would affect whether and how a teacher would hear a student's comment that "the larger the number on the bottom, the smaller the fraction." Knowledge of fractions would also shape the teacher's response: that this conjecture is true only when the numerator remains constant $(1 / 5$ is less than $1 / 3$, but $3 / 5$ is not less than $2 / 4)$.

A third implication of our analysis is that suitably designed assessment tools and curriculum materials can affect teachers' ideas about what is important to teach, and how to understand students' ideas. A mathematics assessment that requires students to justify their answers may not only offer evidence about students' reasoning, but also encourage teachers to include mathematical explanation and reasoning as crucial instructional goals; similarly, developing rubrics for such work and scoring students' responses may help teachers develop more refined ideas about the elements of mathematical explanation and justification. Curriculum materials that unpack the subtleties of the ideas can 
help teachers expand their knowledge of the subjects they teach and thereby better equip them to apprehend and interpret students' knowledge and performance. ${ }^{12}$

A fourth implication is that the teacher's role in using students and materials to produce instruction and learning is therefore distinct, and distinctly prominent, in any conception of instructional capacity. For materials do not use students or teachers, though they can be adapted for better or worse use by teachers and students. It is true that students do use teachers and materials, and that a part of instruction is teaching students to use them better. In fact, teachers who take the time self-consciously to help their students learn to use these elements of instruction will more likely have students who can profit more from what teachers say and offer. However, teachers are uniquely situated to mediate the interactions between and among themselves, students, and materials.

Teachers' Opportunities to Learn. Teachers' opportunities to learn are therefore likely to be a crucial feature of improving instructional capacity. If interventions enable teachers to change what they see in students' work, how they set tasks, and how they interpret and deploy materials, they are likely to have a distinctive impact on teaching practice and student learning. ${ }^{13}$ To do so, teachers would need opportunities that were rooted in specific academic content, that explored and tested out well-designed curriculum materials for that content, and that offered convincing information about students' thinking and performance. Such opportunities would help teachers learn more about their students and the materials of instruction by grounding teachers' learning in improved student performance of particular content. Significant is that these kinds of opportunities would coordinate ex- periences with material and learners rather than omitting one or the other of those crucial elements, or leaving it to teachers to connect separate knowledge of each. ${ }^{14}$

\section{Instruction and Its Environments}

Instructional interactions are situated in larger environments, and intervenors who try to influence instruction must work in those environments. One cannot understand the instructional relationships above, or intervenors' work in them, without understanding the circumstances in which they occur and the opportunities and constraints they present. The environments vary within and among systems and states in the U.S., and they vary among national school systems as well. These environments comprise potential influences on and resources (both positive and negative) for instruction. Whether and how elements of these environments affect instruction, however, depends on how teachers, administrators, parents, and others interpret, respond to, and use them. ${ }^{15}$

Schools. The most immediate environment of instruction is the school, its departments and grade-level groupings. Most of the human, financial, and material resources available for instruction are made available by schools. The school also is the physical and social context within which teachers and students routinely interact. Schools also are the key agent in mediating relationships across classrooms and teachers and between the school and other influences outside the school. $^{16}$

There is extensive evidence that U.S. schools with the very same formal structure dispose the central functions of instruction very differently. ${ }^{17}$ A minority of schools work very hard to create unified instruc- 
tional purposes and methods, while others do nothing of that sort, leaving it to individual teachers to decide. A minority of schools assiduously coordinate instruction internally, but most others appear to do no such work, again leaving it to individual teachers to decide whether even to attend to the matter. In a minority of schools the principal, who sits at the peak of the formal organization, plays a prominent role in deciding instructional issues, but in many others principals leave such matters to individual teachers' discretion. Some schools carefully control the access that environmental influences have within them, but most are very porous. In such porous schools, instruction is idiosyncratically open to influences beyond their schools' boundaries. ${ }^{18}$

This poses a great challenge for intervenors who seek to improve instruction, in part, because critical instructional resources are so often lacking. For example, few schools share common instructional purposes, and even fewer employ instructional methods consistently. Standards for students' performance rarely are explicitly articulated and concretely shared. Where some such articulation occurs, teachers still are usually left to determine how best to meet common goals and standards. Means are widely proclaimed to be educationally distinct from ends. The idea that schools should coordinate instruction internally-to ensure that students' opportunities to learn are coherent within and across grade levels-seems unusual in schools' practice; few schools seem to have the means of establishing or sustaining such coordination. In addition, few principals enact their role as that of an instructional leader; though many now claim such a role, in practice few know how to do such work and most leave such matters to individual teachers' discretion. Intervenors that seek to improve instruction thus must solve a host of problems, or find ways to enable schools to solve them.

System Organization. Larger environments surrounding schools do little either to foster demanding instruction or to encourage instructional improvement. One reason is organizational: the formal structure of the school system is fragmented, which proliferates interventions and messages about instruction at many levels and from many sources. In fact, the school system is in many respects a non-system, a host of more than 100,000 schools situated in 15,000 independent local governments, 50 state governments, hundreds of intermediate and special district governments, as well as multiple federal agencies and countless private organizations. Authority for schools is divided among federal, state, and local education agencies, and within those levels it is divided among legislative, executive, and judicial branches of government. And while formal responsibility for schooling rests with the government, most agencies with expertise in the core technologies of instruction are in the private sector. States delegate most responsibility for assessment to private corporations, and follow the same course with texts and other materials. Teacher education and continuing education are managed by a combination of colleges, universities, private-sector professional entrepreneurs, or professional standard-setting bodies.

Some states, school systems, and schools try to exert a strong influence on instruction, but most do not. A few states try to coordinate the work of private sector agencies, but this is unusual. The result is a general pattern of passivity and uncoordination, punctuated by sharply contrasting efforts at several levels of government and in several private sector agencies, to order instruction more rationally. The extraordinary fragmentation of 
organizations increases the probability that many different messages about instruction will flow toward teachers and students from literally thousands of different agencies. That proliferation of different and often contradictory advice encourages diffuseness in the messages sent and received. From the intervenors' perspective, this means that they are likely to be seen as just one among many competing sources of advice and resources. If they are to help schools improve instruction, they must find ways to make their agenda central to schools' work and screen out many competing messages.

Coordination of Instruction. Despite this fragmented organizational structure, if the agencies worked in close concert on the central functions of instruction-curriculum, assessment, and teacher educationguidance for instruction could be strong and consistent. But there is little such coordination, and that is another reason that the environments of instruction do little to foster demanding instruction or to encourage instructional improvement. Some private publishers offer coordinated curricula and assessments, but many more assessments are developed with little reference to curriculum. Professional development is usually unrelated to either curriculum or assessment, and requirements for teacher education and licensure are similarly unrelated to standards for curriculum and assessment. Guidance for instruction from these sources is profuse, often inconsistent, and only intermittently supports strong academic work. There is a greater volume of guidance in the United States than in other nations: teachers and students are deluged with assessments, programs, policies, judicial decisions, instructional materials, advice from pressure groups, and much more. But the guidance is often inconsistent and unclear, in part because the volume of diverse advice overloads cognitive capabilities and encourages superficial acquaintance and misconceptions. ${ }^{19}$

Professional Norms. If professional norms, standards, and knowledge formation were strong and consistent, the lack of coordinated guidance for instruction would be less troublesome for knowledgeable professionals. Working in their particular contexts, teachers could nonetheless develop their practice within a frame of professional norms, standards, and knowledge. But professional norms are strong on individualism and weak on content, common expectations, and standards. So while most teachers' inventory of practical knowledge grows over time, it typically does so idiosyncratically. The culture of teaching is individualistic, with each teacher developing his or her own style, even within the same schools. Even teachers who regularly talk with colleagues have little concrete in common to discuss. Strong professional norms could help to socialize new teachers to high standards of professional performance, but they rarely do for the norms that have little to do with the content of teaching and learning, and instead tend to support the notion that teaching requires basic technique complemented with a large measure of personal style.

Lacking consistent social guidance or collective experience, knowledge for teaching in the United States arises mostly in individual experience. Teachers' knowledge is nested in particulars, and they interpret and adapt in context, building ideas, habits, and practices as they go. They primarily work alone, with their own students, and their interpretations and decisions are tailored to the specifics of their situations. There is little sense of an accumulation of practical professional knowledge.

Intervenors that seek instructional improvement thus must not only find ways to buffer 
teachers from disparate guidance for instruction, but also to work against the prevailing norms that maintain practice as an autonomous sphere of private discretion.

\section{Resources for Professional Education.}

Preservice professional education could build a strong foundation to help teachers cope with these problems, but it generally does not. Moreover, schools, districts, and states offer teachers inadequate opportunities to learn while at work. A good deal of money is spent on professional education in the United States, but most goes to sponsor inservice activities which are intellectually superficial, disconnected from deep issues of curriculum and learning, fragmented, and non-cumulative (Cohen and Hill, 1998; Little, 1993). Rarely do the inservice activities seem based on a curricular view of professional development. Teachers are thought to need "updating" rather than opportunities to learn about curriculum, students, or teaching. Leadership for professional development is also scant.

One reason for this situation is that professional education often promotes the message that each teacher has to figure out his or her own way, that teaching is as much a matter of personal expression as it is professionally structured and normed (Huberman, 1980; Buchmann, 1993). Another reason is that many administrators and other specialists are not able to offer help in instructional improvement. Only a few of the many organizations involved with schooling have more than a few specialized staff members in the core areas of instruction: teaching, learning, students, curriculum, and assessment. Most of these individuals are deeply committed to education and they work hard, but there is little incentive for them to develop their knowledge and skill and weak support for their work.
The absence of rich resources for professional education, combined with the absence of norms for common work on instruction, means that all sorts of professionals involved in U.S. schools lack language-an intellectual and practical vocabulary and syntax, and knowledge underlying such language-with which to describe and analyze teaching and learning. The absence of such a language, and other resources for the study and improvement of teaching, are another reason for instructional weakness in the environments of schooling. ${ }^{20}$

As a result, when intervenors seek to improve instruction they must work with schools which have inadequate professional resources. Efforts to enact schoolwide change therefore require intervenors to design ways for teachers and administrators to adapt and construct knowledge, and to develop language and norms of discourse that enables concrete work on improvement.

Professional Learning. Instruction is not organized to support learning and improvement. As a result there is often little communication among professionals about teaching or learning. ${ }^{21}$ To the extent that teachers learn from their work, they learn alone, and in this sense the messages teachers receive in their professional preparation have predictive validity. Rather than preparing teachers whose orientation is professional and who expect to work with other professionals, teachers are taught to see their work as personal and idiosyncratic. Teacher education thus often reinforces the existing conditions of work. In addition, most schools make little room for learning about teaching and learning, and other local and state education agencies do even less. Teacher education rarely provides teachers with common language, standards, and norms that would join them with colleagues, linking their interpretations, judgments, and 
decisions. Instead, teachers are intermittently offered bits of theoretical and practical knowledge, and left to learn mostly on their own. As a result, in most cases chance alone separates learning from merely "having experience."

Most comprehensive instructional interventions imply that teachers have a great deal to learn, but neither instruction nor the apparatus of teacher education are organized to support such learning. The success of comprehensive interventions thus depends on intervenors either making provision for such learning or finding ways for schools or other agencies to do so.

Issue-Attention Cycle. The effects of weak and diffuse guidance for instruction are compounded by rapid change in the instructional environment. The attention spans and issue agendas of many agencies are short, so the content of many activities-including policymaking and school improvementtypically shifts frequently. Many elected officials are more concerned with making a mark by legislative or executive action than building programs or policies that might bear fruit over a decade or more. Policy agendas thus shift rapidly, and policymakers often flit from issue to issue in quick succession. The culture of rapid innovation that characterizes U.S. education complements the fickle nature of policymaking. One new fad rapidly succeeds another, curricula are "updated" on regular cycles, new vocabularies emerge and fade. The flush of novelty animates the practice landscape, but little permeates instruction (Cuban and Tyack, 1995; Tyack and Tobin, 1994; Cohen, in preparation). Practitioners have come to expect that most policies and programs will fade after a few years, and have learned that mechanical compliance or lip service is sufficient response. Rhetoric changes much more rapidly than practice.
Patterns of instructional innovation compound the problem. Schemes to improve teaching and learning have proliferated since the 1950s, with the result that, at nearly any point in time, American schools are awash in innovative curriculum materials, proposals for teaching or learning, professional and student evaluation, ways to deal with troubled students, extracurricular activities, and more. But most professionals have limited resources with which to dig deeply into instructional improvement, and most innovators adapt either by devising products that require only quick and superficial attention, or by defining success in ways that are linked to the production of products rather than their use. What results is a culture in which doing something new is valued, while taking instructional renovation seriously-as a matter requiring sustained design, construction, and remodeling-is rare.

One result of this situation has been a perverse sort of social selection: the policies and innovations that have the greatest appeal are those least likely to produce any substantial change in teaching and learning. It is an environment in which something is always new, and many things that were new last year will soon be forgotten. Because agendas shift frequently, the opportunities for substantial instructional improvement are modest.

One consequence is that intervenors work in environments in which neither practitioners nor innovators have experience with deep or sustained work on the improvement of practice. Instead there is a general expectation that instructional improvement does not require sustained effort, and school professionals learn to marginalize interventions, treating them like peripheral ornaments rather than opportunities for significant learning and change. Intervenors who seek serious instructional improvement thus must 
find ways to change such expectations in the schools with which they work; failing that, they can only adapt to the schools' approach and hope that their efforts will meet a better fate than most.

Society and Culture. A final reason that the environments of instruction do not foster demanding instruction or encourage instructional improvement is social and cultural. Schooling is valued by many Americans, but the social and economic supports for instructional effort-from parents' involvement with students' schooling to universities' and business firms' attention to students' school records-are relatively weak. ${ }^{22}$ Only a minority of parents in the United States regularly spend much time with their children on school assignments, compared to parents in other nations. ${ }^{23}$ In many nations, teachers are respected figures, teaching is a respectable career, learning is highly valued, and the popular culture supports hard work in school. In the United States, however, teachers are often figures of fun, teaching is not a respected profession, and the popular culture features money, glamour, sex, and violence more prominently than learning.

Business firms and institutions of higher education send mixed signals about the value of hard work and high achievement in school. Most colleges and some firms send strong messages about the value of hard work and high achievement to a modest minority of academically ambitious students and their teachers. But most students and teachers receive rather weak messages about the value of academic achievement. Relatively weak social support for instructional effort reinforces rather than offsets the school system's academic weaknesses.

Intervenors working in this environment must find ways to buffer the schools with which they work against messages from popular culture and other agencies, to create a culture of hard work and serious academic effort, and to attach or call attention to rewards for school success.

The environments in which practice and policy intersect lack many of the resources that would support fruitful interaction, including a shared language of professional discourse, traditions of common work on teaching and learning, opportunities for professional learning, social and economic support for demanding instruction, and professional norms and incentives that support improvement. Instead these environments are marked by rapidly changing policy agendas, diffuse and often divergent guidance for instruction, deep disagreement about the ends and means of schooling, and inconsistent support for instructional improvement.

\section{Issues and Implications for Intervention and Research}

If intervenors cannot rely on existing arrangements for consistent support in improving instruction, they must devise means to solve such central instructional problems as setting goals, devising means of coordination among units of instruction, deciding upon and enacting methods of instruction. ${ }^{24}$

Intervenors that seek serious instructional improvement therefore face a dilemma. If they can compensate for these environmental conditions they are likely to increase the probabilities of success. But such work is time-consuming, expensive, and difficult to accomplish. Alternatively, intervenors can try to use existing environmental conditions in ways that might bring some success in schools. This approach is likely to be less time-consuming and expensive, but its success in implementation is riskier. 
Many interventions try to improve instruction from the outside-in: they focus on formal organization, resource allocation, or regulation of instruction. ${ }^{25}$ Examples include state standards-based reforms; state, local, or national accountability schemes keyed to assessment results; state and local curriculum regulation and resource allocation schemes; and various organizational reforms, including restructuring, decentralization, site-based management, charter schools, and choice. But the intended instructional effects are only likely to occur if intervenors are able to carry the intervention into the central instructional functions mentioned above. For example, teachers' learning how to use improved curriculum is not typically part of standards-based reform, school restructuring, and other interventions, but is needed to connect broad standards and assessments to the central functions of instruction. Lacking those connections, enactment is likely to repeat typical patterns of highly variable and frequently superficial effects on practice and learning.

The recent Kentucky and Texas reforms offer useful cases in point. Both are versions of standards-based reform, and both link statewide educational standards to annual tests, and schools' test performance to rewards and punishments. Both are regulatory reforms instituted at the state level, but there are significant differences between them. The Texas reforms include assessments at every grade, while Kentucky assesses students at only three grades. The Texas assessments appear to be a criterionreferenced test with each grade-level assessment embodying a set of desired achievement outcomes for that grade; the Kentucky assessments offer a more complex array of outcomes and assessment formats and are difficult to interpret. ${ }^{26}$ The Texas assessment instruments are released to teachers and the public on the assumption that if the outcomes are desirable it makes sense to teach to them while the Kentucky assessments are secured.

Texas offers more opportunities to connect the broad structural elements with the central instructional functions of schools.

Texas teachers and families get evidence on student and school performance every grade and every year, while Kentucky teachers and families receive evidence on three grades. Publication of the Texas assessment instruments creates opportunities for Texas teachers and parents to teach to the test, which is to say, connect the assessment to curriculum. In Kentucky, test security and the lack of means to connect assessments and classroom work have made it difficult for teachers to make connections among assessments, standards, curriculum, and instruction. We are not touting the Texas system, but noting that even two such relatively crude regulatory schemes can differ greatly in the extent to which a broad framework for regulating education is carried into the central functions of instruction. The more complete the carry-through, the greater the chance of change in teaching and learning.

Other interventions try to improve instruction from the inside-out: they focus on elements of instruction or closely related matters, including professional development, new technologies, family involvement, new curriculum, and improved pre-service teacher education. Rather than dealing with formal organization, regulation, and resource allocation, these efforts occur in the very domain that the outside-in approaches typically ignore. But these inside-out efforts typically focus on only one element in isolation from the others. If the central problem of outside-in intervention is making connections to instruction, the central problem of inside-out intervention is coordination among the central instructional func- 
tions, and coordination across classrooms or schools. Examples of such coordination include: setting common goals for instruction within or among classrooms, or among schools; and coordination of instruction itself, assuring that students and teachers deal with the same or similar material within grades, and that student work on successive grades builds on rather than repeating or ignoring what went before. Without the means to set common instructional goals or to coordinate among such elements as instructional methods, curriculum content, information about students' performance, and teachers' opportunities to learn, enactment is likely to be both variable and superficial.

The roles of professional development, curriculum, and assessment in the recent California mathematics reforms are illuminating. ${ }^{27}$ Beginning in 1985, state officials and math educators in California made efforts to align math curriculum and teaching with disciplinary knowledge and to pay more attention to students' thinking about mathematics. To support these ambitions, new curriculum was written, professional development opportunities were created, and new assessments were devised. Research on these efforts reveals that, like most other interventions in the core of instruction, these initiatives were typically carried out in an isolated and uncoordinated fashion. For example, many elementary school teachers had some professional development in connection with the reforms, but most of it was general, not focused on curriculum for students, and not affording teachers consequential opportunities to learn about mathematics, math curriculum, math teaching, or students' mathematics learning. ${ }^{28}$ There was no evidence that these professional development experiences had any consequential effect on teachers' practice. Similarly, most teachers had few or no opportunities to learn about new curricula that was consistent with the reform effort. They would be poorly informed users if new materials showed up in their school or classroom. And, although the state education department wrote new mathematics assessments that were consistent with the new frameworks, only a small fraction of teachers had opportunities to learn about the sort of work students did on them, or to use that work to deepen their knowledge of mathematics and how students think about it.

Most California teachers lacked key elements of instructional coordination: knowledge of what curriculum to teach; what desired student work would look like; operational goals for instruction; and opportunities to learn about such matters. Research showed that neither teachers' practice nor students' achievement changed discernibly for such teachers, a result familiar to reports of uncoordinated and superficial enactment in many earlier studies of innovation. But research in California also showed that a minority of teachers had opportunities to study the sort of curriculum advocated by the state mathematics reforms. The curriculum of teachers' professional development was the curriculum that students would study: teachers had opportunities to learn about the purposes and methods of the curriculum, and to consider how it might be taught and learned. Some teachers who scored state assessments were also exposed to and had some opportunities to learn about the mathematical work state officials wanted students to do. The curriculum for teachers' professional development in these scoring workshops was the students' mathematical work; teachers had opportunities to learn about the nature of the state assessment and the curriculum implied in it, and about how students dealt with the tasks that were presented in the state's new assessments. 
In effect, a small minority of California teachers had occasion to coordinate curriculum with teaching, assessment with learning and teaching, and professional development with both. Such opportunities are entirely atypical of instructional interventions, but they were consequential in California: research showed that teachers who had such learning opportunities appear to have revised their goals for math instruction. That is not surprising, for there was a consistent relationship between and among a curriculum for professionals' learning that was tied to the intervention, the purposes of the intervention, assessment and teachers' knowledge of assessment, and the student curriculum. Though only a small minority of teachers had opportunities to create this internal coordination, it seems to have counted for students: schools having more teachers with such coordinated knowledge had students with higher math scores on the state assessments.

These points suggest that, given the unique nature of instructional environments in the United States, effective intervention seems to require more than managing the innovation. Intervenors may also have to find ways to create alternative instructional environments that buffer many features of the existing environments. Lacking that, intervenors can try to encourage enactors to manage the environment, or try to frame the intervention in ways that would enable it to survive. From an analytic perspective, then, the instructional environment is not simply a "context," a backdrop against which action occurs. It is also part of the content, because the content and process of instruction depends on its environments and because intervenors' and enactors' management of instructional environments will be crucial for their success.

\section{Intervention}

From a perspective of practice, the previous discussion implies that intervention includes extensive work on two fronts: reconfiguring instruction and its environments. There would be important costs to such work, for it expands intervenors' management agenda, complicates problems of quality control, and increases uncertainty. Every intervention can be interpreted as an effort to find an effective balance between comprehensiveness and manageability.

We expect that interventions will be more likely to succeed the better they deploy the elements conventionally associated with instruction. These elements include a teacher or teaching agent; actively engaged learners; a curriculum of intervention; framing the teaching and curriculum in light of an understanding of the learner-enactors and what they bring (because that will affect interpretation and enactment); opportunities to learn, practice, revise, and reflect; examples of successful performance; support from other agents in the immediate environment; and more. Each of these elements can be seen as a set of influences on enactment, and intervention strategies can be interpreted as different configurations of those sets.

Deploying these elements is more easily said than done. Some of the conditions refer to matters that are or could be relatively well under the control of intervenors, including: a teacher or teaching agent; a curriculum of intervention; framing the teaching and curriculum in light of understanding the learner-enactors and what they bring; and examples of successful performance. We discuss these below in terms of intervention design, specification, and development. 
But other conditions are relatively less well under intervenors' control, because they depend jointly on enactors, intervenors, and the instructional environment in which they both operate. These include: engaged learners; opportunities to learn, practice, revise, and reflect; and support from other agents in the immediate environment. Despite their relative lack of control in these matters, managing them is a requirement of successful intervention. We discuss these later in connection with enactors.

Design refers to both strategy (what intervenors include as a target of their efforts), and their conception of improvement (the vision of the improvement process that intervenors embrace and employ in work with enactors). Design bears on the "intended" intervention, that is, the intervention as it is conceived by intervenors. One element of design concerns the specific target of an intervention. Does it aim at all the elements of instruction or just one or two? Does it also take account of the instructional environment? We expect that intervention designs which are more comprehensive and more focused on instruction are likely to be more effective in changing instruction.

The content of comprehensiveness depends partly on assumptions about the purposes and means of school improvement. The key distinction here concerns approaches to capacity-building. Some intervenors emphasize the achievement of a given type or level of instruction by providing teachers and others a defined body of knowledge and skill, while others emphasize helping teachers and others learn to develop resources for improvement by constructing knowledge in and from practice. Most interventions incorporate some elements of both, of course, but the balance varies considerably among interventions, and those differences influence the process of capacity-building. To- ward one end of the continuum, instruction is improved by developing better ideas, practices, and material technologies and giving these to teachers to implement. To build capacity is to provide new technologies, or to provide teachers with new knowledge and techniques which they can then apply. On the other end of the same continuum, change agents help practitioners learn how to improve instruction as part of their practice. Teachers then are able to develop professional knowledge and skills, including understanding of subject matter and knowledge of students, learning, and pedagogy, as they learn in and from practice. Teachers who work in this way are able to play a different role in improving instructional capacity than those who receive and implement intervenors' or other experts' knowledge. Practice itself becomes a site in which to generate knowledge for improving instruction. Intervenors help teachers become both the agents of instruction and the agents of instructional improvement.

The two approaches are likely to have different benefits and costs. The first, although not easy to accomplish, reduces the early and middle-run costs of specifying and developing an intervention and is more likely to produce interventions that many schools can adopt and enact, and that will produce positive change in many schools. But enactors may have something like algorithmic knowledge and skills: they will be able to do what they have been taught, but may have difficulty developing and improving instruction beyond that. The second approach increases the early and middle-run costs of specifying and developing an intervention and is less likely either to produce interventions that many schools could enact or to produce positive change in many schools. But if schools did enact such things well they would be more likely to have deeper and more supple knowledge of instruction. 
They would have a much more difficult time learning to improve instruction, but those that get beyond that will be more likely to develop further and improve instruction.

Instructional interventions are not mere designs. Each is accompanied by some effort to define, explain, interpret, and develop their meaning and entailments for action. Some interventions have relatively little such stuff; in our terms they are specified and developed in rather spare form. Others include quite a bit of this, and in our terms they are more fully specified and developed. ${ }^{29}$ We expect that the sophistication with which interventions are specified and developed will have a considerable effect on their implementation. ${ }^{30}$

Specification refers to the explicitness with which an intervention is articulated and mapped-to the plans for action, including what the intervenor chooses to treat explicitly and how. Hence we refer to the plans or educational blueprints for intervention, including plans for a curriculum for enactors' learning, plans to collect and use evidence on enactment, and much more. Historically, many interventions consisted chiefly of statements of principles and goals that suggested a general direction but little more; some deliberately restricted themselves to such on principle or for fear of inhibiting enactors. Specification in such cases was spare.

Only a few recent intervenors offer much in the way of specification. An example would be setting out the terms of a curriculum for enactors' learning (what teachers and others involved in carrying out the intervention would need to learn and where or how such learning might be profitably arranged), and setting out the content of that curriculum would be further specification. Although specification could mean detailed blueprints for an intervention, it need not. For the nature of appropriate specification of an intervention would depend on its design-that is, its purpose and content. For instance, the content of an intellectually ambitious curriculum could be specified in terms of its objectives, its main themes, the types of activities entailed, and examples of the sort of work that should result along with examples of inadequate work. Such specification would offer users a great deal of guidance without constraining their choice of materials, the order of operations, or other things. Specification need not impede practitioners' autonomy or inventiveness; like any materials for learning, specification of an intervention can either open up or constrain opportunities to invent and exercise autonomy.

Analysis of specification would also include what is specified-that is, what do intervenors spell out in detail and what do they leave to local or individual wishes? For example, intervenors often provide explicit detail about the curriculum to be used with students, but leave unspecified how teachers might learn this new curriculum themselves. What interventions specify and how they do so will affect their role and influence in directing and encouraging learning, managing change, and building instructional capacity.

Development refers to the action repertoire of interventions, including materials for enactors; social processes such as professional development; working models or examples of adoption processes, or video materials that depict teachers' knowledge, norms, and skills in ways that would be educative for other teachers; and social processes for involving and educating parents. ${ }^{31}$ If the specification of interventions is analogous to planning for instruction, then development is analogous to creating materials, occasions for instruction, and processes that would provoke and support the learning thus 
planned. ${ }^{32}$ The effects of specification seem likely to operate chiefly through processes of development, rather than independently.

Development refers to creating the organizational, social, and intellectual resources required to enact interventions. Building curricula for enactors' learning is an example of relatively strong development; simply mentioning such a curriculum would be an example of weak specification and no development; ignoring the matter entirely would be weaker still. ${ }^{33}$ As with specification, development can be accomplished in ways that offer extensive guidance without constraining invention and autonomy, or in ways that are quite constraining.

Complex social innovations offer many choices for development, and which elements of an intervention are developed is as important as the richness with which they are developed. For example, one important element in development is whether it includes a role for teaching in the intervention; another element is whether resources are identified for those who would act as teachers for enactors. As in curriculum for children, the critical issue is the delineation of the teacher's role and the development of associated guidance for teachers, not just what opportunities are created for students. Another element is the extent to which curricula for enactors' learning attends to the community in which enactors would be working and trying to learn. For example, interventions could be developed in ways that provide resources for enactors to work collectively, to share information, to encourage and support greater interdependence of effort, or in ways that provide no such resources and assume that enactors would learn and work alone.

\section{Implications for Intervention and Research}

We pause again to derive several points from the frame sketched above concerning both the design of interventions and research on them.

In order to have any hope of success, intervenors must create designs for intervention, write some sort of specifications, and develop materials and processes that will help enactors learn in light of those designs and specifications. Such designs, specifications, materials, and processes for enactment are what educators will need as they try to improve teaching and learning. The more fully intervenors design, specify, and develop interventions, the more guidance they offer to enactors, and thus the greater the probability of success for those enactors. Less is left for enactors to invent on their own. But such interventions may not always be the best choice, for the more fully intervenors design, specify, and develop interventions, the greater the intervenors' costs. Furthermore, many enactors may be averse to more fully designed, specified, and developed interventions, either because the explicit design enables them to see that they do not like aspects of the intervention or because they are averse to such seemingly prescribed work.

There is a big trade-off between two idealtypical approaches to intervention. The more intensive types reduce uncertainty and define areas for rational action through careful design, specification, and development, which raise the costs of intervention. The more conservative types moderate costs with more loosely designed, specified, and developed interventions; these allow enactors more autonomy to tailor interventions to their own purposes and context, but also they increase uncertainty and reduce areas of bounded rationality. 
Intervenors who take the first approach use careful design, specification, and development to detail enactment. They use knowledge of enactors to design the intervention so that it is as usable as possible. If intervenors adopt this approach they assume extensive responsibility for teaching the intervention and seeing that it is learned. But how intervenors enact an intensive approach depends partly on the nature of the intervention. One version, for interventions that are susceptible to direct instruction, is to detail enactors' learning and action. Intervenors who take this approach do something analogous to curriculum developers who seek to devise curriculum for independent learning-that is, they write programmed materials that closely specify what is to be learned and the processes for learning it. The idea is that learners will acquire the skills and understanding that they need by following the curriculum as written. At the extreme, such programmed learning materials usually leave little or nothing to be developed by the learner: the steps, the materials, the cognitive and other processes, the monitoring, are all incorporated. ${ }^{34}$ The aim is to reduce variability at every stage of design and enactment.

Another version of this approach, for interventions that are less susceptible to direct instruction, is to specify and develop materials and processes that enable intervenors to offer rich experiences in which enactors can re-invent the intervention, but do so in ways that satisfy openness to enactors' constructions and fidelity to the design. If the first approach is a version of programmed instruction, this second is a version of guided discovery. There is elaborate design and rich specification and development in both cases, and intervenors and enactors would have close relationships in both. But the nature of these things would vary with the purposes and content of the intervention. ${ }^{35}$
Enacting the conservative approach sketched above can vary appreciably. Intervenors could design and specify the intervention by enunciating only principles and leave nearly everything else in the way of specification and development to enactors. Some intervenors take this path on the assumption that the nature of the intervention and the complexities of enactment would be violated by detailed specification. A contrary approach is to design, specify, and perhaps even develop the intervention in detail, but to delegate enactment entirely to those who would adopt it. In either of these more conservative approaches, intervenors limit their responsibility to making some knowledge of the intervention available. Like many teachers, they "put it out there" and let those who can "get it" do so, while those who cannot, do not. Intervenors do not accept responsibility either for enactors' learning or for extensive curriculum and instructionresponsibilities which intervenors who take a more intensive approach actively embrace. The more conservative approaches allow intervenors and enactors to have a looser relationship, and encourage local adaptation and invention.

Few intervenors design, specify, and develop interventions in one of the extreme ways sketched above, but in one of the many different degrees that lie between the extremes. One way is to shade design, specification, and development in a coordinated way, in one of the many degrees that separate intensive from conservative approaches. Another way is to mix and match within an intervention, designing some elements in an intensive manner and others more conservatively. Purely intensive or conservative approaches to intervention are unlikely. The question for every intervenor is where they will position the intervention: how much intensive work can they afford to do, and 
how much can they afford to leave to enactors?

Intervenors must manage the trade-offs between reducing uncertainty and bounding areas for rational action through careful design, specification and development on the one hand, and on the other hand moderating the costs and associated difficulties of intervention by requiring less design, specification and development, by allowing enactors more autonomy to adapt the intervention to their purposes and situations, which also increases uncertainty and reduces areas of bounded rationality. ${ }^{36}$ In the first approach, specification and development increase the opportunities for intervenors to teach and enactors to learn how to manage change and build instructional capacity, and they refer to extensive designs, materials, and processes. But such specification and development entail steep costs, hence some intervenors may leave many particulars of the intervention to enactors to decide and invent locally.

This analysis implies that there exist different views of specification and development, some better suited to more conservative intervention and open adoption, and others better suited to more intensive work. The very meaning of the integrity or fidelity of enactment for those having a conservative view could be very different from those having a more intensive view of intervention. Specification and development could refer to loosely and weakly defined designs, materials, and processes. These differences may be related to the purposes and content of intervention. An intervenor whose design for change is premised on a behaviorist view of learning is likely to have a very different conception of specification and development than an intervenor who adopts a radical constructivist view of learning. Not only would specification and development be more or less salient, they might be salient in different ways, depending on intervenors' designs.

While we expect that the specification and development of an intervention will significantly affect its enactment, it will be important to relate the meaning of these terms to intervenors' strategies. For intervenors seem to have different strategies. Some may see their work as a matter of beginning to familiarize broad segments of American education with new ideas which, if successful, would take generations to develop. Others may strive to create models that can be widely enacted within a decade or two. Such strategic differences imply varying conceptions of what enactment means. If so, intervenors may hold different views on the yield of their work. Some may see relatively weakly implemented versions of an intervention in many sites as preferable to deep implementation of a much smaller number of versions in a few sites, because they envision a slow process of diffusion. While depth and fidelity would be the chief criteria of impact in some strategies they would be less appropriate for others, at least in the short run.

\section{Enactment}

Everything in the preceding section focused on intervention, as if the only salient causal relationships ran from intervenors to classrooms, through instructional environments. But most intervenors deal with schools, and they work in mostly voluntary relationships, so that all intervenors depend on the schools that they wish to improve. In the case of government intervenors, the most important source of voluntarism is decentralized school governance, which leaves state and federal agencies with less authority and influence than localities in most educational domains, and thus politically dependent for acceptance of interventions by local educa- 
tional agencies. The ostensible objects of policies and programs have enormous influence over both higher-level executive and legislative designs and enactment, which creates incentives for intervenors to respect enactors' wishes.

For non-government intervenors, the most important source of voluntarism is that they can only work with enlistees who choose to do so, and who therefore have a good deal of independence. Intervenors have no formal relationship with schools or school systems other than those that enactors choose. That could create incentives for intervenors to respect enlistees' wishes, but intervenors might instead define the process of enlistment in ways that deliver only enlistees who wish to improve and seem eager to do it as proposed by the intervenor. So intervenors would work with enactors who were deeply committed to the intervention and to highfidelity enactment. From the perspective of most intervenors, those would be ideal enactors. But whatever intervenors and enactors do, their mutual definition and management of the process of enlistment is likely to be central, both to the formation of intervenors' strategies and to enactors' response. $^{37}$

The forms of voluntarism and compulsion somewhat belie the realities. Relationships that appear to be compulsory in state and federal policies have very strong elements of local autonomy and choice. And relationships that appear to be entirely voluntary may have strong elements of obligation precisely because they arise from mutual choice.

A further and powerful source of voluntarism for intervenors in and outside of government arises from the nature of instruction itself. We pointed out earlier that intervenors can offer resources of various sorts, in- cluding inducements, money, education, and the like, but such resources are used or not, and used well or poorly, by enactors-that is, teachers, students, and others in their vicinity. Some researchers and reformers regard such resources and outside agencies as causes of instruction, however, we treat them as resources. They can become causes-that is, they can influence practice-only as teachers and students recognize, accept, and enact them. Such resources, including entire interventions, are potential; only teachers and students can use them, and they can use them only as they are able and inclined. Intervenors can only drive if enactors drive as well, and share the driver's seat with them.

Against this background we see increasing numbers of schools which have either strong incentives or explicit obligations to improve. In Kentucky, San Francisco, Chicago, New York, and elsewhere, the weakest performing schools have been placed in forms of receivership, "reconstitution," or "crisis." There are strong elements of voluntarism in the relations between intervenors and enactors, even in these seemingly extreme cases. One reason is that some compulsory schemes have elements of local choice: many reconstituting schools are given choice among interventions, and some-in Kentucky, for example-are encouraged to compose their own remedies. Another reason is that state agencies have little capacity in a decentralized system to actually intervene in many schools; hence they tend to work with small numbers of the very worst schools, leaving most poorly performing schools to their own devices. ${ }^{38}$ Mutual choice may be a stronger source of obligation than compulsion in all but the most extreme cases.

In any case, our analysis implies that intervenors must solve a central problem in 
framing and managing their relations with enactors: will intervenors define improvement and the processes leading to it in ways that center most responsibility in enactors or in themselves? Choosing the former course will create incentives to define tight relations with enactors, to carefully select enactors, and to define improvement and the processes leading to it quite explicitly. Choosing the latter course will create incentives to define loose relations with enactors, to admit enactors relatively freely, and to define improvement and the processes leading to it in a more relaxed fashion.

Our analysis also implies that enactment entails a complex set of relationships between intervenors and enactors, between enactors and the environment, and between intervenors and the environment. Intervenors and enactors need to manage all elements of these relationships. Enactors should be understood as managing interventions and intervenors, just as intervenors are understood as managing interventions and enactors.

The ways in which intervenors and enactors manage each other will depend partly on how intense or relaxed the intervention strategy, but either approach implies continuing communication and exchange of resources. And since their mutual management occurs in instructional environments that offer few supports for extensive or enriching instructional relationships, intervenors and enactors do not begin by working in anything like the stable relationships between most teachers and students. The creation of stable relationships-in which commitments and resources can be regularly exchanged between intervenors and enactors, and in which they can conduct other important transactions-turns out to be a central task of intervention. ${ }^{39}$
If intervenors offer highly specified and developed interventions, they will be more likely to build extensive management systems to support the intense relations with enactors that such interventions require. These management systems must be added into the costs and benefits of different intervention strategies; their existence will increase the probability of high-fidelity enactment, but will add to the human and fiscal costs of intervenors' work. Such management systems also may raise the ante for enactors because they increase surveillance and quality control. ${ }^{40}$

Solving these problems of mutual choice and continuing relations is further complicated by intervenors' and enactors' organizational settings. Most intervenors appear to be temporary: their funding is soft, often quite speculative, and subject to change in foundation and government agendas. Intervenors' relations with recruits are voluntary, and they appear as an organization that most school professionals have seen come and go many times. In contrast, enactors work in public schools that appear more permanent: schools are part of governments that typically have existed for decades or more. Schools have relatively steady budgets that are settled in apparently stable state and local budget lines. Despite intermittent funding problems, schools' core budgets do not need to be raised anew every few years. Although some schools close, some students disappear, some parents are unhappy, and some budgets shrink, these problems have not been normative for the enterprise. Several decades of opinion research show that the overwhelming majority of parents are quite satisfied with their local school.

There are few strong incentives, as this sketch implies, for potential enactors to improve instruction. Therefore, potential enactors have few strong incentives to enter 
into intense relationships with intervenors. Non-government intervenors operate in markets, and must find and satisfy clients, while public schools operate in the grants economy where few must search for clients. Government intervenors operate in a climate of political voluntarism, in which the objects of policies and programs have great influence, both over higher-level executive and legislative designs and over enactment. In both cases there are strong incentives for intervenors to make connections with enactors that will not displease them and that will not require either the termination of many relationships or repeated searches for new recruits.

One implication of this analysis is that, from the enactors' perspective, the default option has been to marginalize-that is, to use the resources that interventions bring while retaining the core of operations unchanged. ${ }^{41}$ This strategy requires the least learning and change and has worked very well in U.S. education. $^{42}$ Marginalizing interventions keeps the ratio between costs and benefits of enactment in a manageable range and enables enactors to innovate and improve without basic change. ${ }^{43}$ In the typical U.S. instructional environment, it is entirely rational. From the typical enactor's perspective, the preferred relationship with intervenors keeps things loose and permissive, with intervenors supplying resources and enactors deciding how to use them. Such a conservative approach could include some regular relations-annual meetings, occasional visits, newsletters, and other informal communications-but it would not include efforts to check on the fidelity of enactment. Intervenors and enactors would be linked in a loose but mutually beneficial network in which knowledge, skills, and other resources could be exchanged without greatly taxing anyone's resources.
To have any hope of success, intervenors must devise intervention strategies to deal with this situation. One strategy is to specify interventions loosely and require only intermittent interaction with enactors; that would conform to extant preferences and practice. Another strategy is to focus intervention on a select group of relatively highachieving enactors for whom the problem is more easily solved. Still another strategy, for those who contemplate intensive work around carefully specified and developed interventions, is to devise ways to attract enactors who would accept stable and tight relations with the intervenor, fundamental change and extensive learning. Another strategy still is to routinize large elements of the intervention so as to reduce costs to intervenors and uncertainty for enactors. There are other alternatives, including combinations of the strategies mentioned here.

An intensive intervenor-enactor relationship is likely to require management of the instructional environment. And the more active and complex that relationship, the closer enactors and intervenors would be to the creation of new sub-systems of schooling. Though these sub-systems would be temporary, unofficial, and nongovernmental, they could serve several purposes: to screen out competing instructional guidance, to help stabilize funding and political agendas, and to create some measure of professional community. But the prospect of such tight relationships is likely to be unsettling to many schools and the districts that sponsor them. Intervenors that propose more conservative and relaxed relations with enactors would ease such worries by allowing enactors to cope with the instructional environment themselves, and thus allowing interpretation of the intervention to vary.

Our discussion implies that incentives for school improvement are a critical variable in 
the relations between intervenors and enactors. The more that potential enactors are under internal or external pressure to improve instruction, the greater the probability that they will find it useful to accept intervenors' specifications and close relationships with them. The more that potential enactors are under pressure to demonstrate results, the more likely they are to accept highly specified and developed interventions which promise to produce such results. But to say that incentives are important is not to say which incentives would be best. Many commentators favor external incentives tied to state or local accountability systems, but it is not yet clear whether these schemes actually mobilize much improvement effort. ${ }^{44}$ Others favor incentives associated with local administrative pressure and support for professional performance, but such endeavors are few and far between, and there is little evidence on their effects.

\section{Implications for Intervention and Research}

We pause once more to set out several implications for the analysis of both intervention and research on the relations between intervenors and enactors.

If we were to order the ideas about building capacity discussed above in a formal causal model, we would represent intervenors' influence on enactors as partly constructed by those enactors. Causal arrows would run in both directions between external agents and influences on one hand, and enactors on the other. ${ }^{45}$ This bi-directionality would apply to resources in the immediate instructional environment as well as to more distant potential influences.

One critically important element of instructional capacity is enactors' ability and disposition to notice instructional problems, and the ability and disposition to recognize and use the resources that would be likely to help solve those problems. Yet when intervenors work in poorly-performing, highpoverty schools, almost by definition they work in situations in which those abilities and dispositions are weakly developed at best. In this case, the people who have the problem are the key agents for solving it, yet the problem inhibits both their recognition of it and their adoption of problem solving strategies. External intervenors cannot hope to succeed unless enactors recognize problems and adopt problem-solving strategies, but reaching that point would take great change for many enactors. Those in the most difficult circumstances are likely to be furthest from the required recognition and to work in the most troubled environments. ${ }^{46}$

Intervenors have several strategic alternatives in dealing with this situation:

- Routinize interventions to ease the magnitude of the "recognizing problems and learning to solve them" task for enactors, and the corresponding teaching task for intervenors.

- Select only relatively apt enactors who already are well on the route to recognizing problems and learning to solve them. This could be a matter of restricting enlistment to entire schools based on collective decision-making, or opening enlistment to individual teachers within schools, or both restricting enlistment to entire schools and allowing dissenting teachers to opt out. ${ }^{47}$

- Instruct enactors so that they learn and change-that is, successively reconstruct their initial dispositions and abilities in some instructional process. 
- Define intervention and enactment so loosely as to allow many flowers to bloom, thus allowing enactors to define their own levels of effort and implementation, and the things they will learn.

- Some combination of the first three strategies noted here.

Building capacity can, like many other schooling problems, be treated as a problem of selection alone, of learning alone, of combined selection and learning, or of treatment definition. Recent interventions handle this matter quite differently.

\section{Conclusion}

This report offers a significantly different approach to understanding instructional improvement. We summarize the distinctive elements and advantages of our approach and the implications for instructional change.

Capacity. First, we see capacity as specific. Most discussions of instructional capacity seem to assume that instructional capacity is generic, but our analysis suggests that capacity always refers to what it takes to do some specific thing. If so, the nature of capacity varies with the direct object of the phrase ". . .capacity to. .." In considering instructional capacity, then, one must recognize that instruction varies greatly-for example, between teachers who cultivate students' ability to reason and those who inculcate facts and skills. It seems likely that such differences would entail substantially different capacities, for what teachers would need to know and be able to do could vary enormously depending on whether instruction is aimed at inculcating basic skills or cultivating rationality.
Since instruction occurs in interactions between teachers and students around educational materials, capacity resides in these interactions. Each of these elements is essential; instruction requires all three. Any of the three elements can influence capacity for instruction, but they act only insofar as they influence the other elements. In our view, then, isolated initiatives like curriculum reform or restructuring are unlikely to improve instruction. Improved capacity depends on affecting the ways in which teachers, students, and materials understand, make use of, and influence one another.

Our perception implies a dynamic view of the endowments of instruction. Many commentators conventionally refer to what teachers or students bring to instruction, arguing that capacity may be diminished when they bring less to the instructional table. While there is some truth to that, our analysis suggests that what teachers, students, or materials bring to instruction depends partly on how well it can be discerned and used by teachers. In this view, endowments can be understood not as an absolute feature of a teacher, student, or bit of material, but as a function of how well other interactors can make use of the endowment. It follows that to improve capacity would be to affect how teachers, students, and materials understand, make use of, and influence one another. Changing such understanding is likely to be a very potent intervention, apart from any other change in instructional technology or organization.

This perspective offers a more flexible conception of capacity, which seems better suited to the many different situations that are presented in a single classroom in a single day. It also enables a more situational understanding of capacity, which should help us make sense of the different interac- 
tions among teachers, students, and materials.

Capacity and Teacher Learning. Many discussions of instructional capacity assume that some individuals or institutions have it while others do not-that capacity can be understood as a store of knowledge and skill to be deployed at will. From this viewpoint, once capacity is built, it is there to be used as needed. This helps explain why professional development is often seen as a primary strategy for capacity-building: if teachers learn special methods and develop improved understanding of the curriculum, their capacity will increase. Teachers who learn more are thought to have more capacity, hence the continuing appeals for more and better professional development.

We have tried to show that instructional capacity could not reside only in knowledge of content or pedagogy, and that it could not be the pure possession of teachers or instructional technologies. If capacity arises in interactions among teachers, students, and materials, then any given element of instruction shapes capacity, and thus performance, by the way it interacts with and influences the other elements. But teachers play a distinctive part in these interactions for they guide and shape them. Their knowledge of and skill at interpreting and making instructional use of materials and student ideas is crucial.

It follows that improving knowledge and skill of instructional interaction is a particularly salient feature of instructional improvement. This means that teachers' opportunities to learn such knowledge and skills are likely to be more productive than learning content or methods alone. Helping teachers hear and see more in student work, helping teachers learn how to intervene artfully in student work and to motivate stu- dents, all affect what students can learn to do. The most effective teacher learning is likely to focus on instruction-as-interaction, rather than on isolated elements of instruction.

\section{Capacity and Instructional Environments.}

Most capacity-building efforts appear to assume that interventions could be independently effective; most efforts to improve instruction in recent decades have focused on interventions alone. Curriculum developers and teacher educators have acted as if they assumed that teaching and learning could be treated as independent of their environments. In contrast, our theoretical frame assumes that the environments of instruction are critical to intervention: to intervene in instruction is to somehow manage those environments.

The chief reason for this view is that the United States is inhospitable in many respects to serious instructional improvement. The environments in which capacitybuilding efforts operate lack many of the resources that support improvement-a shared language of professional discourse, professional socialization leading to shared norms and standards of work, traditions of common work on teaching and learning, opportunities for professional learning, social and economic support for demanding instruction, and professional norms and incentives that support improvement.

Given the nature of these instructional environments, effective intervention must go beyond managing the innovation. Intervenors must find ways to create alternative instructional environments (and buffer out many features of the existing environments), they must delegate such work to enactors, or they must frame the intervention in ways that will endow it with survival value in the unusual environments of U.S. education. We there- 
fore treat the instructional environment not as a backdrop against which action occurs, or as part of its context, but as part of the content of that action.

Managing the Environment. This analysis implies that intervenors face imposing tasks if they seek to manage instructional environments. One high priority would be the creation of new guidance for instruction while managing the extant busy and often chaotic guidance system. Another priority would be creation or adaptation of learning opportunities for enactors. Still another priority would be building infrastructure for communicating about the intervention, which would require the establishment of regular links between intervenors and practice. And, intervenors and enactors would have to find ways of managing persistent political conflict and overcoming the lack of strong incentives for improvement.

Designing, specifying, and developing are the three key elements of interventions. Design refers to overall goals and strategy. Specification refers to the plans or educational blueprints of policies and interventions, including the curricula for enactors' learning, the nature of the discourse between intervenors and enactors, and more. Interventions usually consist chiefly of statements of principle that amount to very weak designs; they suggest a general direction but little more. In such cases, specification is spare and thin. Only a few interventions seem to offer more in the way of specification.

Development refers to the action repertoire of policies or interventions, including materials, social processes (like teacher education), working models or examples of adoption processes, or video materials that depict teachers' knowledge, norms, and skills in ways that would be educative for other teachers, social processes for involving and educating parents, etc. If the specification of interventions is analogous to classroom plans for instruction, then development is analogous to creating materials, occasions for instruction, and processes that would provoke and support the learning. Betterdeveloped interventions are more likely to effectively encourage learning, manage change, and build instructional capacity.

Careful design, specification, and development of an intervention can reduce uncertainty and define areas for rational action, and thereby increase the likelihood of successful instructional improvement. But this greatly raises the costs of intervention, which may reduce its attractiveness. Alternatively, interventions can be designed with modest specification and development, so that enactors can respond with little or no change in the instructional environment. That moderates the costs of intervention and is attractive to enactors because more loosely designed, specified, and developed interventions allow enactors more autonomy. One cost of this approach is increased uncertainty about effective intervention and enactment; a second cost is reduced areas of bounded rationality. A third cost appears to be variable and often superficial enactment, and thus a decreased likelihood of successful instructional improvement. ${ }^{48}$

Our theoretical frame also bears on the problem of moving from small to large-scale enactment. Most discussions suggest that this is a quantitative problem, a matter of getting broader adoption and implementation. Our analysis suggests that these problems are qualitative, not quantitative, but solving them is a necessary condition for spreading innovations. One problem is designing, specifying, and developing interventions in a manner commensurate with the task at hand, ${ }^{49}$ and a second problem is 
building infrastructure for managing the environments of intervention so that they would support both intervention and enactment. Solving these problems would require extensive qualitative change in interventions and their environments. The move from small- to large-scale enactment is as much a qualitative problem of designing more elaborate interventions and building instructional environments as it is a quantitative problem of more adoptions.

Enactment. Efforts at school improvement rest on profoundly different constructions of the situation. Most efforts to build instructional capacity are made by agents, situated outside schools or classrooms, who try to improve what happens inside. These agents have a diagnosis of how and why schools have failed and methods for setting things right. While some enactors share the sense of failure, many locate the problem elsewhere and believe that no solutions exist. Schools cannot be improved unless these differences can be somehow negotiated and resolved. What is more, intervenors have relatively weak leverage in the situation, for their relationships with enactors are mostly voluntary in political, organizational, and technical terms. Intervenors can offer inducements and other resources, but these are only potent as teachers and students recognize, accept, and enact them. Intervenors' influence thus is partly constructed by enactors, and intervenors depend on schools because schools must choose to enlist and because schools must then make use of what intervenors offer. Intervenors and enactors operate in something like a market in which intervenors work only with enlistees who chose to work with them, and who have a good deal of independence.

These relations are further shaped by time horizons and resource flows. Most intervenors have only temporary funding and few or no political sponsors, while schools have more permanent funds, are sponsored by the state, and have clients who are mostly satisfied with the school their children attend. In such a situation intervenors and enactors are likely to define their relations quite differently. Intervenors would prefer only enlistees who wish to improve and seem eager to work as the intervenor proposes, because that greatly simplifies the tasks of intervention, checking compliance, and the like. In contrast, enactors are likely to prefer access to the resources that interventions bring while retaining the core of operations unchanged, because that reduces the work to be done and enables educators to adopt many interventions while keeping all of them on the margin. Any school improvement effort must deal with these very different constructions of the situation and courses of action.

Intervenors that seek high-fidelity enactment and thus cultivate intensive relationships with enactors will be drawn to more active management of those relations and the instructional environment. The effect would be to create something like new sub-systems of schooling that could screen out competing instructional guidance, stabilize funding and political agendas, and create some measure of professional community. Such work would further raise the costs of intervention while possibly reducing some risks of variable and low-fidelity enactment. The less intervenors cultivate intensive relationships with enactors and seek high-fidelity enactment, the less need there would be for elaborate sub-systems. This approach would reduce the costs of intervention while increasing the risks of variable and lowfidelity enactment.

This analysis implies that incentives for improvement will be a critical variable in relations between intervenors and enactors. The 
more that potential enactors are under internal or external pressure to improve instruction, the greater the probability that they will accept intervenors' specifications and make close relationships. The more that potential enactors are under pressure to demonstrate results, the more likely they are to accept highly specified and developed interventions, which are more likely to produce such results. But it remains unclear which incentives will be most effective. For instance, there are schemes to mobilize external incentives by holding teachers accountable for student performance on assessments, but there is little evidence yet that such schemes alone mobilize much effort at improvement. Other sources of incentives-those associated with local administrative pressure and support for professional performance and those associated with enlistment in interventions-have been investigated less, but may have elements that support improvement.

Intervention and Instruction. We have framed intervention as a form of instruction. If enactors are to make use of the resources that intervenors offer, intervenors must help enactors learn how to recognize and diagnose problems, identify and use resources, solve the problems, or find enactors who already are able to do those things, or both. Intervenors' approaches vary, but all act from an external position in schools or classrooms in order to encourage the professional actions that will improve instruction. ${ }^{50}$ Such action by external agents can be seen as a sort of teaching.

Intervenors and enactors work together on an agenda for implementation, which comprises a species of curriculum. Most interventions require considerable learning for enactors, and no intervenor can rely purely on improvised tutorials. Whether we consider a huge state reform like the California math frameworks, QUASAR'S work with a handful of schools, or a new curriculum adoption in a district, there is some explicit or implied curriculum for enactors. But the nature of that curriculum varies, from rudimentary to elaborately developed and selfconscious designs for learning an intervention.

But curriculum is not enough. Just as teachers cannot cause students to learn, intervenors cannot cause enactors to do the intervenors' will. Only enactors can learn an intervention, and their efforts to do so will be influenced by their knowledge, skill, and will to learn, and by the instruction that intervenors offer. Intervenors working with high-poverty schools face a distinctive problem: the school professionals, parents, and others whose schools perform poorly are also the key agents for improving those schools. Yet the problems of such institutions and of poverty inhibit the recognition of problems and the adoption of problemsolving strategies. External intervenors cannot succeed unless enactors recognize problems and try to solve them, but reaching that point implies enormous change for many enactors. We identified several strategic alternatives that intervenors have in addressing this situation:

- Routinize interventions to ease the magnitude of the enactor's task of recognizing problems and learning to solve them, and the corresponding teaching task for intervenors;

- Select only apt enactors who already are well on the route to recognizing problems and learning to solve them;

- Instruct enactors so that they learn and change-that is, successively reconstruct their initial constructions in some instructional process; 
- Define intervention and enactment so loosely as to allow many flowers to bloom, thus allowing enactors to define their own levels of effort and implementation and the things they will learn;

- Some combination of the first three strategies noted here.

Building capacity, like many educational problems, can be treated as a problem of selection alone, of learning alone, of combined selection and learning, or of treatment definition. $^{51}$

This frame focuses attention on both instructional relationships and mutual selection in intervention. It implies that interventions will be more likely to succeed if they effectively deploy the elements conventionally associated with instruction. These elements include a teacher or teaching agent; actively engaged learners; a curriculum of intervention; framing teaching and curriculum in light of an understanding of the learner-enactors; learning opportunities for professionals; and more. The more extensive intervenors' instructional designs, the more opportunities that enactors have to learn and the more likely that enactors will learn. Some interventions deploy these elements in relatively spare ways, while others deploy much richer versions; in our terms the latter are more specified and developed. We expect that the richness with which interventions are specified and developed will affect their implementation.

Another implication of this analytical frame is that ability and disposition to notice and act on instructional problems, and ability and disposition to recognize and use resources that could help solve those problems, are critically important elements of instructional capacity. Cultivation of these abilities and dispositions in enactors is one important element in any effort to improve instructional capacity. The effectiveness of the instruction that intervenors offer is likely to depend heavily on their ability to help educators learn very different things about what they and their students can do.

This analysis implies a new view of the core technology of interventions. Interventions propose to change what teachers and students know, believe, and can do, hence they operate by means of ideas, beliefs, professional norms, and intellectual practices. These are central to intervention because they are the stuff of instruction. If knowledge, ideas, beliefs, and intellectual practices are the key agents for enacting intervention, that implies a distinctive view of how politics, organization, and other such factors influence instructional improvement. Instead of considering politics and organization as influences only in their own right, we expect their influence to be mediated by the instructional relationships summarized above. That influence can occur in at least two ways. One is by impeding or enabling ideas and practices, for example, the impediments that the fragmented organization of U.S. schools offers to the formation of professional communities and thus to deliberate learning about professional practice. In this case, the macro structure of school politics constrains opportunities for professionals to learn in and from practice. Politics and organization also influence how problems are framed; for example, the battles over basic skills and critical thinking influence decisions about the content, adoption, and evaluation of interventions. These culture wars place constraints on the aims and content of tests, curriculum, and teacher education. In both examples, the importance of politics and organization is expressed in the context of instructional relationships. 


\section{References}

(Incomplete; many are listed in endnotes only)

Buchmann, M. (1993). "Role over person: Morality and authenticity in teaching." In M. Buchmann \& R. E. Floden (Eds.), Detachment and concern: Conversations in the philosophy of teaching and teacher education, (pp. 145 - 157). New York, NY: Teachers College Press.

Cohen, D. K. (in preparation). Teaching and its predicaments. Manuscript in preparation: University of Michigan, Ann Arbor, MI.

Cohen, D. K., and Hill, H. C. (1998). Instructional policy and classroom performance: The mathematics reform in California. Philadelphia, PA: Consortium for Policy Research in Education, University of Pennsylvania.

Cuban, L., and Tyack, D. (1995). Tinkering toward utopia: A century of public school reform. Cambridge: Harvard University Press.

Huberman, M. (1980). Finding and using recipes for busy kitchen messages: A situational analysis of routine knowledge use in schools. Prepared for the Program on Research and Educational Practice: National Institute for Education, Washington D.C.

Little, J. W. (1993). "Teachers' professional development in a climate of educational reform." Educational Evaluation and Policy Analysis, 15 (2), 129-151.

Tyack, D., and Tobin, W. (1994). “The 'grammar' of schooling: Why has it been so hard to change?" American Educational Research Journal, 31, 453-479. 


\section{End Notes}

${ }^{1}$ We include as "intervention" state policies, private initiatives (like new text series or the National Board of Professional Teaching Standards), school reform networks, and other efforts to improve instruction.

2 "External" here refers to being outside the direct interplay of teachers, students, and curriculum; hence it may refer to staff members in the local central office, state or federal legislators, or private sector agents.

${ }^{3}$ Readers who want a quick overview of the ideas should read the conclusion first. We are designing a study on instructional improvement that is informed by the ideas in this report. A detailed research design and proposed sampling frame are available under separate cover.

${ }^{4}$ Doyle (1984) highlights the importance of distinguishing the "enacted curriculum" as it is constructed by teachers and students.

${ }^{5}$ Recent scholarship on teacher knowledge covers more than these elements and domains. See for example: Ball, D. L. and Wilson, S. W. (1996). "Integrity in teaching: Recognizing the fusion of the moral and the intellectual." American Educational Research Journal, 33, 155-192; Schon, D. (1987). Educating the reflective practitioner: Toward a new design for teaching and learning in the professions. San Francisco: Jossey-Bass; Sockett, H. (1987). "Has Shulman got the strategy right?" Harvard Educational Review, 57, 208-219; Tom, A. (1984). Teaching as a moral craft. New York: Longman. For purposes of the distinction we are making here between resources for teaching and resources for the construction of knowledge in teaching, we deliberately compress and streamline our map of teacher knowledge here. In developing instruments for our research, we will want to both elaborate and broaden the lenses with which we examine instructional capacity.

${ }^{6}$ We use the word "knowledge" here to refer to understandings, conjectures, theories, and ideas. For example, when we say "knowledge about the discourse of classrooms and how that discourse affects what students learn," we mean theories about such, and acknowledge that ideas about this important domain differ among researchers and practitioners, as well as among those who aim to reform schools.

${ }^{7}$ In the moment, of course, one often cannot know that something being learned is general rather than specific to the moment and the situation.

${ }^{8}$ Each of these alternatives implies certain attributes of learning, and, taken together, they tell us a great deal about how teachers try to construct students' learning in a classroom: that is, how students will treat knowledge, how and how much they will open their thinking to teachers, and what sort of discourse they will engage in. Several of these categories are taken from Cohen, D. K. (in preparation). Teaching and its predicaments. University of Michigan, Ann Arbor, MI.

${ }^{9}$ The sheer number of leverage points may not be crucial; more is not necessarily better. What matters is how and on what intervenors work, with what emphasis and intent, and how those de- 
cisions impact instructional capacity. For example, new mathematics materials may influence capacity more than similar materials might in reading, because math is less dependent on the social environment. We want to learn what sorts of interventions on which elements precipitate what sorts of changes in instruction. It may be that certain strategic points of intervention produce more powerful effects on instruction than other, more voluminous and varied intervention strategies.

${ }^{10}$ See for example Peter Dow's (1993) account of the development and implementation of Man: A Course of Study. Dow, P. (1993) Schoolhouse politics. Cambridge, MA: Harvard University Press.

${ }^{11}$ For a longer discussion, see Ball, D.L. (1997a). "What do students know? Facing challenges of distance, context, and desire in trying to hear children." In B. Biddle, T. Good, and I. Goodson (Eds.), International handbook on teachers and teaching (Vol. II), (pp. 679-718). Dordrecht, Netherlands: Kluwer Press.

12 These ideas are drawn from Ball, D.L. (1997b). "Developing mathematics reform: What don't we know about teacher learning-but would make good working hypotheses?" In S. Friel and G. Bright (Eds.), Reflecting on our work: NSF Teacher Enhancement in K-6 Mathematics, pp. 77 111. Lanham, MD: University Press.

${ }^{13}$ As above, we are not arguing that all learning opportunities need to be direct or explicit. However, interventions that leave teacher learning to chance are unlikely to work as well as those that attend in some way to teachers' learning opportunities.

${ }^{14}$ Some of our other research shows that when learning opportunities for teachers are grounded in the students' curriculum, the learning affects both teachers' practice and their students' learning more significantly than other sorts of professional learning. Cohen, D. K., and Hill, H. C. (1998). Instructional policy and classroom performance: The mathematics reform in California. Philadelphia, PA: Consortium for Policy Research in Education, University of Pennsylvania.

${ }^{15}$ We develop these ideas about resources in Cohen, D. K., Ball, D. L., and S. Raudenbush (1999, April). "Educational resources and instruction." Paper presented at the annual meeting of the American Educational Research Association, Montreal, Canada.

${ }^{16}$ Moreover, this structure is remarkably homogenous: there is little variability within the U.S. in this structural dependence. All schools constitute classrooms and other internal units (such as departments and multi-grade groupings). The chief area of variability is grade structure: all high schools are internally departmentalized by school subject or academic discipline, while all elementary schools are not.

${ }^{17}$ Some researchers and intervenors appear to assume that because classrooms are structurally dependent on schools they are also functionally dependent. They argue that the school's formal pre-eminence means that it is or should be the central unit for investigating instructional processes and effects. Some intervenors argue, in roughly parallel fashion, that schools are the pri- 
mary unit for improving instruction. But there is no necessary relationship between structural and functional dependence.

${ }^{18}$ School systems differ in this respect. In some national systems, schools' formal organization is closely linked to the arrangements for instruction. State schools in France, for example, have dealt with the central functions of instruction quite consistently, with relatively little variation within or among schools in instructional goals, methods of coordination, and the like. See for example, Broadfoot, P., Osborn, M., Gilly, M., and Bucher, A. (1993). Perceptions of teaching: Primary school teachers in England and France. London: Cassell. Because the system is centralized nationally, and because professional norms seem quite powerful and homogenous, teachers and administrators appear to agree on these matters, and to agree as well on the relations between formal organization and instruction. The system appears relatively homogenous both within and among schools.

${ }^{19}$ There is some coordination between some governments and some agencies that produce and manage these elements of the core technology: state agencies set standards for teacher licenses and certification, and some states regulate text purchase, but many do so only weakly, and others do nothing.

${ }^{20}$ One cannot imagine physicians and other health care professionals improving either patients' health or medical practice if they lacked the descriptive and analytic languages of physiology and anatomy, of disease processes, and treatment. Such professional language and the knowledge underlying them are at the heart of medical practice, but they are very weakly developed in education.

${ }^{21}$ This communication could occur through sharing student work, presenting lessons to other practitioners, discussing videotapes of teaching, collective examination of curriculum, collective curriculum construction, or joint analysis of student performance.

22 On families and schools, see Stevenson, H., and Stigler, J. (1992). The learning gap: Why our schools are failing and what we can learn from Japanese and Chinese education. New York: Touchstone; and Cohen, D.K. and Spillane, J.P. (1992). "Policy and practice: The relations between governance and instruction." In G. Grant (Ed.), Review of Research in Education, 18, 449. Washington, DC: American Educational Research Association.

${ }^{23}$ Stevenson and Stigler, op. cit.; Cohen and Spillane, op. cit.

${ }^{24}$ A special case of this situation is that a central task of many interventions is to constitute or reconstitute the instructional environment that we call "school." Schools' passivity with respect to instruction means that schools' formal or structural resources cannot be translated into resources for instructional improvement. For this reason many interventions devote significant resources to leadership development, improved decision-making at the school level, and related matters. 
${ }^{25}$ Instructional regulation includes graduation requirements, text adoptions, standards-based reform, and other efforts to use regulatory mechanisms, usually at the state or federal level, to influence classroom work.

${ }^{26}$ See Elmore, R.F., Abelman, C., and Fuhrman, S. (1996). "The new accountability in state education policy." In H. Ladd (1996). Holding schools accountable: Performance-based reform in education, pp. 65-98. Washington DC: The Brookings Institution.

27 This account is based on Cohen and Hill (1998).

28 This seems typical of most professional development in the United States today: teachers engage in a variety of short-term activities that fulfill state or local requirements for professional learning but are rarely deeply rooted in the school curriculum or in thoughtful plans to improve teaching and learning.

${ }^{29}$ Since policies and interventions often are aimed at students but depend on professional educators, what follows applies both to the elements of policy that centers on student learning and to the elements of policy that centers on educators' learning.

${ }^{30}$ Both terms thus refer to and modify intervention design.

${ }^{31}$ Development is not the mere enactment of specification. It is not difficult to imagine a direct instruction scheme that is very highly specified but for which the materials and teacher education are detailed, thin, and mechanistic. The results of development may not express the promises of innovative specification, or they may exceed those promises.

${ }^{32}$ We do not assume that specification and development exist in linear form; often specification is refined as a consequence of work on development.

${ }^{33}$ Instructional interventions of very different sorts can be strongly and weakly specified and developed-specification is not just a matter for more didactic interventions. But specification and development would look rather different for interventions that had modest instructional goals and didactic methods than for interventions that had ambitious instructional goals and flexible methods. When the instructional purposes and methods of policies and interventions are quite simple, then more complete specification and development are possible. Specification and development are more complex and difficult when interventions are more intellectually ambitious and child thinking-centered, and must be less complete because more complex social interactions will ensue. But the greater difficulty and incompleteness of specification and development is not reason to conclude that only broad principles can be enunciated. A great deal can be specified and developed for more complex and ambiguous policies and interventions, but there will be more contingency. Weak specification of such interventions has been more common, both because the work is difficult and because of the mistaken idea that specification and development inhibit creativity, autonomy, or both.

${ }^{34}$ Developers who create such materials sometimes design them in such a way that differences in what learners bring (and the effect of these differences on what they would learn) are muted by 
so closely specifying the desired outcomes and so fully developing the processes and materials to attain them.

${ }^{35}$ Each approach entails efforts to manage the instructional environment, the first by creating a new environment that would both guide instruction and buffer other competing signals, and the second by accepting the existing environment and trying to compete with it.

36 The less well-specified and developed instructional policies and interventions are, the more they leave to be invented, improvised, and figured out-or unwittingly ignored. Such interventions delegate much difficult work to enactors, but they do so tacitly, without exposing much about the nature, extent, or difficulty of the delegated work. What is left underspecified or underdeveloped matters. Recent research suggests that there is a bi-modal response to weakly specified and developed interventions: a small population of enactors deeply engages the ideas and struggles with very complex and difficult learning in the absence of much guidance, while a much larger population-believing that it has engaged the ideas deeply-responds either with modest, superficial, and often distorted practices, or responds not at all. In most cases, then, little guidance from intervenors does not promote enactors' autonomy or creativity, but weak learning and enactment.

${ }^{37}$ In the case of schools in "reconstitution," "crisis," and "receivership," intervenors work with those who did not choose to improve, and who, almost by definition, did not recognize their problems. Even if they chose to enlist with intervenors, the choice resulted from external compulsion. Work with such schools may create different dynamics between intervenors and enactors.

${ }^{38}$ In the decentralized U.S. political system, even when state or local governments require or strongly urge enlistment on a school, schools will have considerable political autonomy. The forms of voluntarism and compulsion may belie the realities: what appears to be compulsory may have strong elements of choice, and what appears to be choice may have strong elements of obligation.

39 These points are implied or explicit in most analyses of implementation, although few analysts give any consideration to teaching and learning as a frame for analysis, and most give different weights to the three considerations above. Some treat all of the considerations as less important than the intervention or policy itself.

40 The management systems that enactors and intervenors create could include the following means of managing relations between enactors and intervenors:

- Professional and technical knowledge alone-intervenors offer professional education, technical assistance, the collection and feedback of data on enactment or some combination of these (which can be very loosely or tightly specified);

- Compliance reviews, in which standardized data collection and/or site visits are used to determine the nature and extent of symmetry with the intervenor's design;

- Extensive mutual exploration and contracting in advance of any intervention, to set expectations, define roles, and mobilize commitment; 
- $\quad$ Placement of an agent (site facilitators, coaches) of the intervenor in enactor's organizations, to both assist with enactment and check progress (site facilitators, coaches);

- $\quad$ Make side bargains with local school agencies to manage the environment (stabilize funding, reduce conflicting messages, etc.); and

- Give enactors strong and detailed guidance for instruction.

${ }^{41}$ See Consortium on Chicago School Research (1996). Charting reform: Teachers take stock. Chicago: Author.

${ }^{42}$ It is worth recalling that such rationality depends in part on an instructional environment in which the incentives for improving instruction are modest at best.

${ }^{43}$ It is possible that some enactors would use interventions to fend off the invasion of other, less desirable, influences or forces. There are some reports of such a response in many professional development schools. Deborah Schifter has reported a similar response to her work, and there is some sign of this with several of the California math professional development projects.

${ }^{44}$ See, for example, Elmore, Abelman, and Fuhrman (1996).

45 That is not to embrace a subjective view of external resources; we do not assert that resources are mere figments of teachers', students', or observers' imaginations. The presence of such potential resources can enable practitioners to reduce the difficulty of good work, just as their absence makes it more difficult to do good work. If two equally able and energetic teachers work in two very different schools-one that has an equally energetic and able faculty and another that does not-the teacher in the better situation will have many more resources to use in doing good work that her colleague in the poorly endowed school. The lack of such colleagues does not prevent good work, but it does make it more difficult. Similarly, the presence of good colleagues or other resources cannot cause a teacher to do good work, though it may create some conditions that would enable such work if the teacher is motivated and able. While institutions can offer teachers rich or poor social resources of practice, only teachers and students can see and use those resources, or fail to see and use them.

46 This is a persistent dilemma of teaching: many teachers and leaders who instruct (whether they work in classrooms, larger organizations, or some body politic) are confronted by many potential learners who recognize no need to learn. It is a condition of their success that these teachers must somehow mobilize the requisite will and skill to learn among these potential learners. At least several of the interventions that we propose to study are such cases, and their success depends heavily on finding ways to solve problems of enactors' recognition of their own problems and adoption of problem-solving approaches.

${ }^{47}$ The proposed research will require that we further develop hypotheses about how the selection might work. This would prominently include the attributes that intervenors would be expected to look for and select on-general aptitude? Affinity for the intervention? Quickness of learning in early acquaintance? Other things? 
48 These two tasks also have been nearly entirely ignored. For example, in their book, Tinkering Toward Utopia, David Tyack and Larry Cuban appear to take innovations as given, as though problems of design and specification did not exist. Yet most of the reforms that they discuss were extremely weakly specified and quite underdeveloped. A similar point holds for managing the environments of intervention-it simply does not enter most analyses.

${ }^{49}$ In the case of simple organizational changes-extending the school day by an hour-this is not very difficult, but efforts to promote intellectually ambitious instruction could require extensive specification and development.

${ }^{50}$ External here refers to the classroom; hence it may refer to staff members in the local central office, state or federal legislators, or private sector agents.

${ }^{51}$ Other educational problems include admission to private schools or to programs within public schools. 